\title{
Investigation of drug use causes in young persons of Sanandaj using Respondent Driven Sampling
}

\author{
Emad El-din Ezatpour ${ }^{1}$, Khaled Rahmani ${ }^{2}$, Farzam Bidarpoor ${ }^{3}$
}

1- M.A in Clinical Psychology, Department of Psychology, Sanandaj Branch, Islamic Azad Univeristy, Sanandaj, Iran. ORCID: 0000-0001-6440-028X E-mail: emad.ezatpoor@gmail.com

2-Assistant Professor of Epidemiology, Department of Community Medicine, Medicine Faculty, Kurdistan

University of Medical Sciences, Sanandaj, Iran. ORCID: 0000-0002-0860-8040

3-MD, Deputy of Health, Kurdistan University of Medical Sciences, Sanandaj, Iran. ORCID: 0000-0003-3199-4266

\section{Abstract}

Received: 08/04/2018

Accepted: 04/09/2018

Introduction: Drug addiction is one of the most important health problems and social harms worldwide. Based on exist evidence primary prevention is main approach for addiction control in the society and treatment could not help to deal with this issue.

Aim: The aim of this study was to determine the causes of drug addiction for the first time in drug users of Sanandaj.

Method: This was a qualitative study that conducted in Sanandaj, 2015 using respondent driven sampling (RDS), as one of the sampling methods to access the hidden population. With this method until saturation of the data 410 addicts were recruited. Focus group discussions (FGD) and in-depth interview methods were used to determine the causes of drug abuse in drug users for first time. Data analysis was performed using Open code software.

Results: Until saturation, 410 addicts were enrolled in the study with a mean age of 36.3 years. Mean age of these patients at first onset of drug use was 17.2 years. The results showed that hedonism (pleasure), curiosity, peer pressure (recommended friends), lack of enough knowledge, having addict person in the family, emotional failures and unemployment have been recognized as major causes of drug use for the first time. Great prosperity and propensity to the mind comfort were other un-prevalent causes for beginning the drug use that reported in some participants.

Conclusion: Given the results, preventive interventions can be carried out for most causes of drug use identified in the study especially paying attention to the needs of these people in their teenage period besides the giving required information to them would be helpful.

Keywords: Addiction, Use the drug for first-time, Respondent Driven Sampling, Qualitative study.

How to cite this article : Ezatpour E E, Rahmani Kh, Bidarpoor F. Investigation of drug use causes in young persons of Sanandaj using Respondent Driven Sampling.. Shenakht Journal of Psychology and Psychiatry. 2018; 5 (3): 12-21 .URL :http://shenakht.muk.ac.ir/article-1-396fa.pdf

Copyright (C) 2018 the Author (s). Published by Kurdistan University of Medical Sciences. This is an open access article distributed under the terms of the Creative Commons Attribution-Non Commercial License 4.0 (CCBY-NC), where it is permissible to download, share, remix, transform, and buildup the work provided it is properly cited. The work cannot be used commercially without permission from the journal. 
مجله روانشناسى و روان بزشكى شناخت

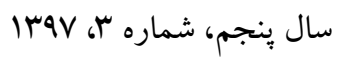

صفحات: |r-r|r

\title{
بررسى علل مصرف مواد مخدر در جوانان شهر سندج با استفاده از روش نمونهيرى نهان
}

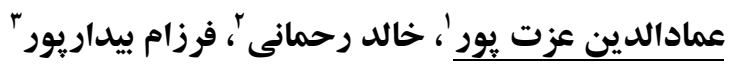

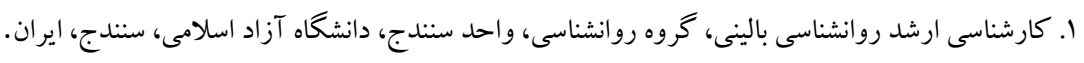 \\ ايميل: emad.ezatpoor@gmail.com

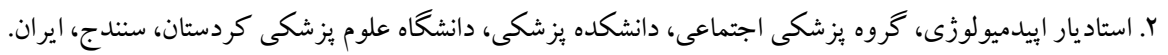

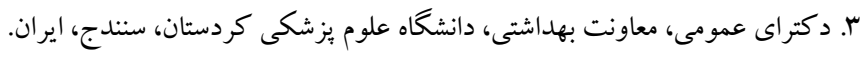

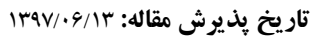

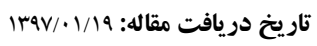

جكيده:

مقدمه: اعتياد به مواد مخدر به عنوان يكى از آسيب هاى اجتماعى و يكى از مهمترين مشكلات سلامتى در دنيا مطرح است. طبق

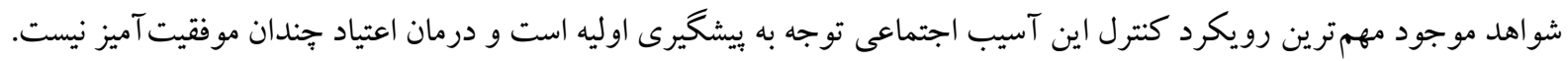
هدف: هدف مطالعه حاضر شناخت علل مصرف مواد مخدر در بار اول در معتادان شهر سنندج بود. روش: در اين مطالعه كيفى كه در سال Farا در سندج انجام شد از روش نمونه گيرى نهان (RDS) كه يكى از روشهاى دسترسى به

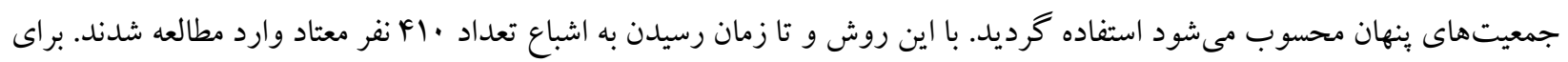

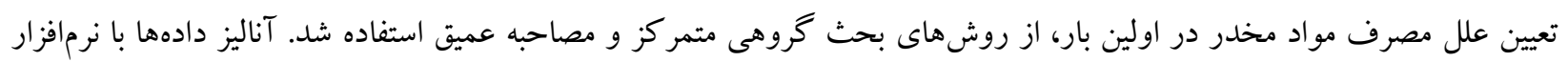
Open code

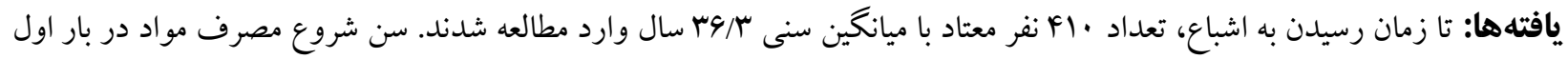

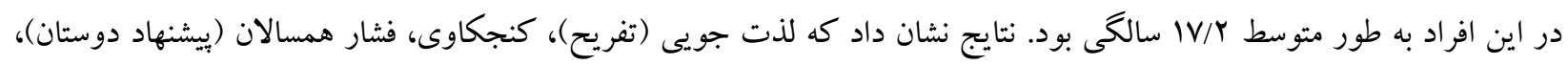

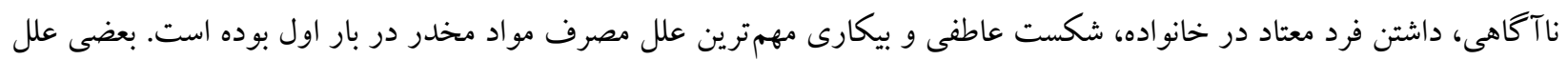

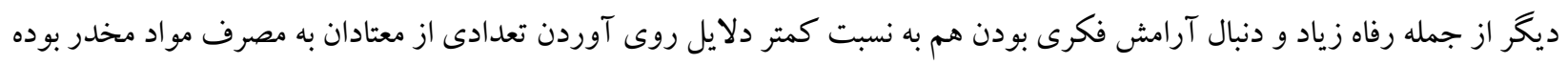

نتيجه كيرى: با توجه به نتايج اين مطالعه، براى اكثر مواردى كه به عنوان علل مصرف مواد مخدر در بار اول شناخته شده اند مىتوان

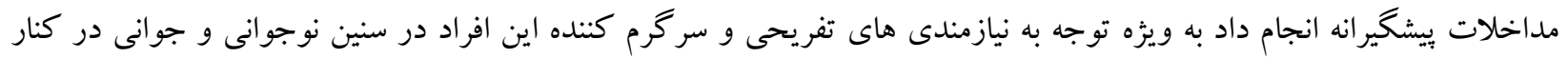

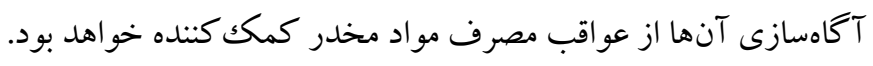

كليدوازهها: اعتياد، مصرف مو اد در بار اول، معتادان، نمونه گيرى نهان، مطالعه كيفى 
در ايران صورت گُ فته است و بر اساس شواهد موجود مى

مقدمه

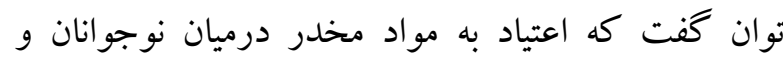
جوانان يكى از جالش هاى مهم نظام سلامت در ايران محسوب مى شود. مصرف مواد مخدر علاوه بر تأثير گذار بودن روى سلامت خود فرد مى تواند خطرى هم براى ساير افراد جامعه در زمينه گسترش بيمارى هاى خطرناكى همجِون اج آى وى/ ايدز، هياتيت هاى B و C باشد. بخش زيادى از مشكلات و آسيب هاى ديخرى هميجون طلاق، بزهكارى، سرقت و.. در جامعه مى تواند معلول اعتياد به سيه مواد مخدر باشند. به عقيده اكثر يزوهشگران هيج گاه نمىتوان يك دليل واحد براى اعتياد معرفى كرد و در بيشتر موارد جندين

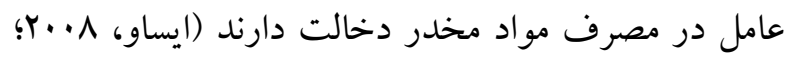
كيناست و همكاران؛

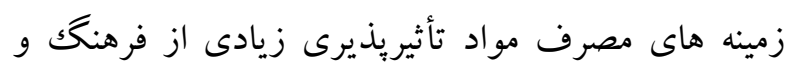
محل سكونت افراد دارد اما عوامل زمينهساز آن بيشتر در سه دسته عوامل فردى، عوامل اجتماعى و عوامل بين فردى قرار مى گيرد. عوامل فردى شامل زنتيك و وراثت، نوجوانى، صفات شخصيتى، اختلالات روانى، نخرش مثبت به مواد، موقعيتهاى مخاطرهآميز، تأثير مثبت مواد بر فرد

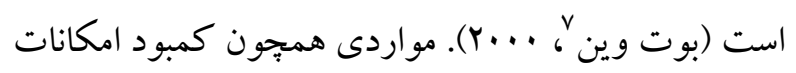
فرهنكى، ورزشى و تفريحى، كمبود امكانات حمايتى خدماتى، درمانى و مشاورهاى، توسعه صنعتى، مهاجرت، وردى كمبود فرصت هاى شغلى، محروميت هاى اقتصادى و اجتماعى، فرهنگ و آداب و سنن خاص، نقص قوانين مرتبط با مواد مخدر، بازار مواد مخدر و وفور آن هم در دسته عوامل اجتماعى قرار دارند و دسته سوم يعنى عو امل

${ }^{6}$ Kienast, Stoffers, Bermpohl \& Lieb ${ }^{7}$ Botvin
اعتياد عبارت است از وابستكى به عوامل يا موادى كه تكرار مصرف آنها با كم و كيف مشخص و در زمان معين از ديد گاه معتاد ضرورى مىنمايد (كودمن'، . 199). بهعبارتىديخر يعنى تداوم بخشيدن به مصرف مواد و عوامل

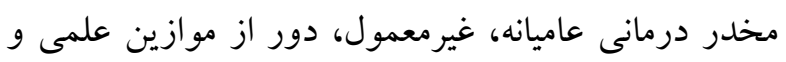
معتاد كسى است كه نيازمند و وابسته روانى -جسمانى به مواد و عوامل مخدر و عادات باشد كه بهمنظور بر آوردن

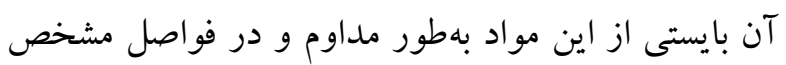

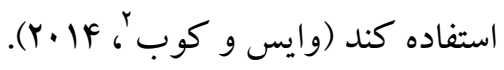

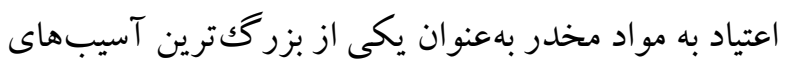
اجتماعى و يكى از مهمترين معضلات جو امع كنونى دنيا

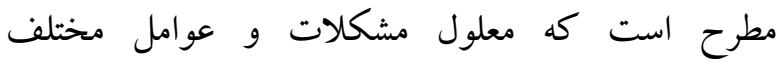

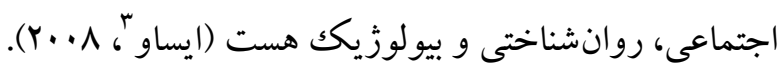
مطابق با داده هاى جهانى در سال •. · در سطح دنيا مشكلات مرتبط با بيمارىهاى روانى و اعتياد در مجموع

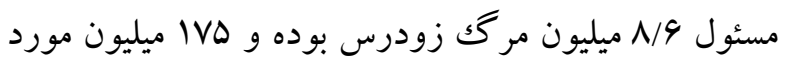

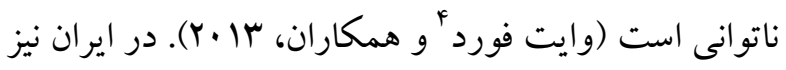
تخمين زده مىشود بيش از Y ميليون معتاد به مواد مخدر مختلف وجود دارد كه حدود . . م هزار نفر از اينها هم

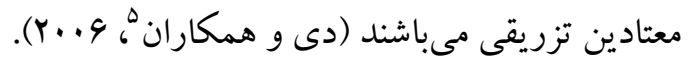
همجنين در مطالعهاى در ايران نشان دادهاند كه حدود سبץ/ دانش آموزان دبيرستانى مصرف يكك يا جند بار مواد مخدر را داشتهاند (احمدى، حسنى، ب...Y). در يكك بررسى ديخر كه در سطح خانوارهاى كرمان صورت گرفته است شيوع

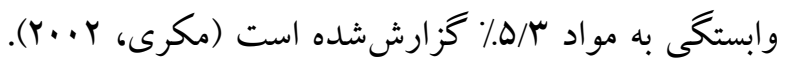
بهطور كلى مطالعات براكنده زيادى در زمينه بحث اعتياد

\footnotetext{
${ }^{1}$ Goodman

${ }^{2}$ Wise \& Koob

${ }^{3}$ Essau

${ }^{4}$ Whiteford

${ }^{5}$ Day, Nassirimanesh, Shakeshaft \& Dolan
} 
و C در معتادان بود كه در سال FaF إدر سنندج انجام شد. در بخش مربوط به بررسى علل اعتياد در معتادان از روش كيفى استفاده شد. متدولوزى مطالعه كيفى بر بايه فنومنولوزى (يديدار شناسى) بوده و معتادان شهر سنندج، جامعه مورد مطالعه يُزوهش بودند. مطالعه حاضر با هدف شناخت علل و عوامل موثر در شروع مصرف مواد مخدر در معتادان شهر سنندج بود. در اين مطالعه از دو روش بحث كروهى متمركزه و و

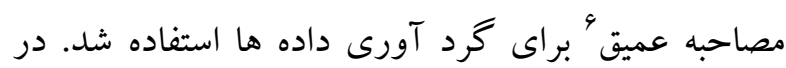

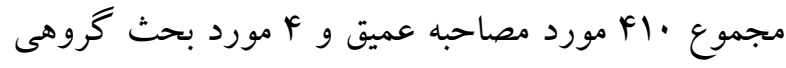

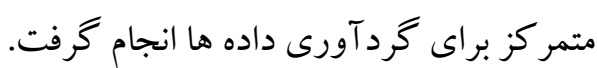
از آنجا كه معتادان در زمره گروه هاى سخت در دسترس براى انجام مراقبت محسوب مى شوند در اين مطالعه براى دسترسى به نمونه ایى قايل تعميم از روش نمونه گيرى نهان يا به عبارتى نمونه گيرى از طريق هدايت نمونه ها (RDS) استفاده شد. براى انجام اين استراتزى نمونه كيرى ابتدا

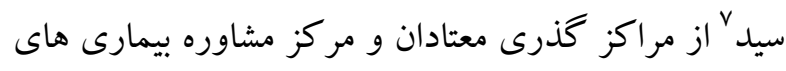
رفتارى وابسته به دانشگاه علوم يزشكى كردستان انتخاب كرديد. در گام بعدى و يس از انجام مصاحبه با اين افراد به هر كدام از معتادان سه برگك كوين داراى شماره سريال مخصوص به هر كدام از اين 9 نفر ارائه شد تا هر كدام سه نفر ديخر را از طريق اين كوين ها به تيم تحقيق معرفى به اله كنند. لازم به ذكر است هر كدام از اين كوين ها يك نوع مشوق براى افراد بود و هر كدام از معتادانى كه با داشتن اين كوين ها به تيم تحقيق مراجعه مى نمودند يس از ارائه

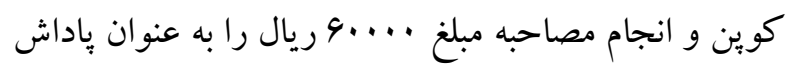
شركت در مطالعه دريافت مى كردند. در اين نوع نمونه كيرى تا حدود زيادى مى توان به طيف متنوعى از معتادان

${ }^{5}$ Focus group discussion

${ }^{6}$ In-depth interview

${ }^{7}$ Seed
بين فردى هم شامل خانواده، مدرسه، محل سكونت و

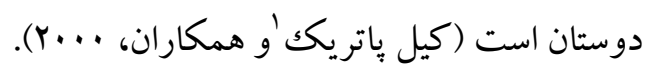

ير واضح است كه در استان كردستان با توجه به فرهنگ

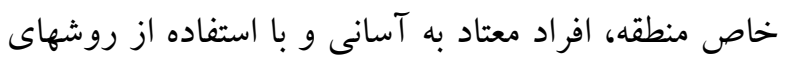
نمونه گيرى معمولى وارد مطالعات نظام مراقبت نخو اهند شد و به نظر مى رسد استفاده از روشهاى نوين نمونه گيرى مهي همجيون نمونه گيرى نهان (RDS مطالعات اعتياد كمك كننده باشد. بر همين اساس در

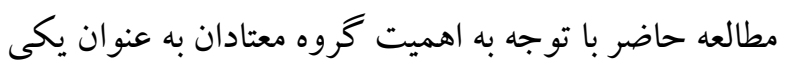
از گروههاى سخت در دسترس، با استفاده از تكنيك RDS كذار در مصرف مواد مخدر بررسى شدند. با توجه به شواهد موجود تاكنون مطالعات خاصى در سطح استان كردستان و شهر سنندج در زمينه علل و عوامل تأثير كذار در شروع مصرف مواد مخدر صورت نخرفته است. از آنجا كه در حوزه درمان اعتياد موفقيت هاى جندانى در دنيا حاصل نشده است (سوبل، سوبل و واردّا

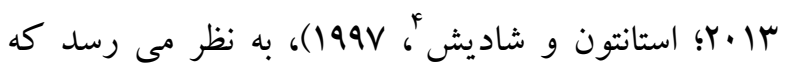
شناسايى علل تأثير گذار مى تواند به عنوان يك كام بسيار

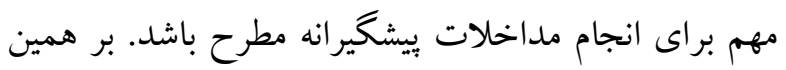
اساس مطالعه حاضر باهدف شناخت علل تاثير گذار در شروع مصرف مواد مخدر در معتادان شهر سنندج انجام كرفت.

\section{روش} مطالعه حاضر به عنوان بخشى از مطالعه بزرگك مر اقبت هاى رفتارى و سرولوزى اج آى وى و هياتيت هاى ويروسى

\footnotetext{
${ }^{1}$ Kilpatrick

${ }^{2}$ Respondent Driven Sampling

${ }^{3}$ Sobell, Sobell \& Ward

${ }^{4}$ Stanton \& Shadish
} 
ييامهاى غير كلامى افراد و تعاملات آنها با يكديخر و با اطر اف را مورد بررسى قرار دهند.

يك راهنماى سؤالات بر اساس اهداف مطالعه به صورت يكك برسشنامه طراحى گرديد كه اين برسشنامه راهنما

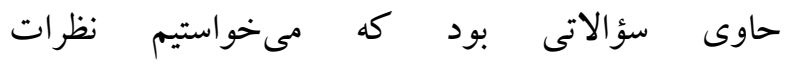

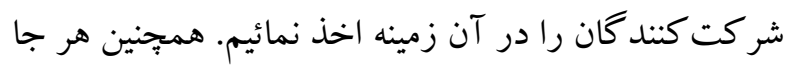
لازم بود از سؤال كاوشى 'نيز براى عمق بخشيدن به بِاسخها استفاده كرديد.

براى تجزيه و تحليل اطلاعات به صورت زير عمل شد ابتدا تمام بحثهاى گروهى و مصاحبههاى عميق ضبط شده

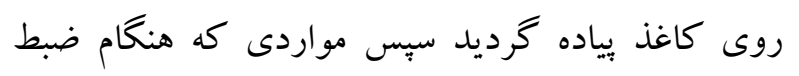
بحث ها و مصاحبه ها يادداشت بردارى شده بودند با مطالب ضبط شده مطابقت داده شدند و هرجا نياز بود اين نكات كه حاوى برداشت هاى انجامشده از اشكال غيروربال شركت كنند گان بود هم به مطالب ثبت شده

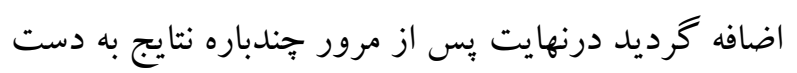
آمده توسط دو نفر از محققين به شكل مستقل تم هاى اصلى استخراج شدند سبس تم هاى استخراج شده توسط

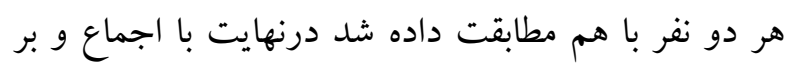
اساس فراوانى نظرات شركت كنندكان تم هاى اصلى بدست آمده دسته بندى گرديدند.

يافته ها براى انجام اين مطالعه در مجموع تا زمان رسيدن به اشباع •l أنفر معتاد وارد مطالعه شدند. علاوه بر انجام مصاحبه عميق با تمام •Fl نفر معتاد بررسى شده، 9 مورد بحث

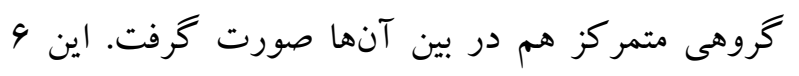

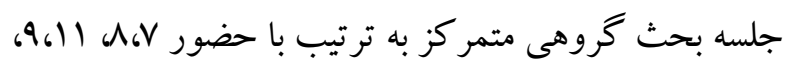

${ }^{1}$ probe question
و بر اساس اهداف و موضوع اصلى تحقيق دست يافت و اين استراتزى (نمونه گيرى نهان) به نوعى هتروزنيتى افراد

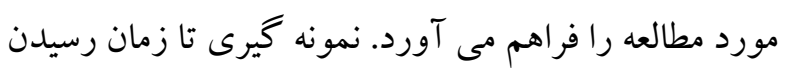
به اشباع در گردآورى داده ها ادامه يافت. داده هاى اين مطالعه شامل نظرات شركت كنند گان در مطالعه بود. نظرات شركت كنند كان در مطالعه در زمينه هدف كلى و اهداف جزئى با يرسشهايى از طريق اخذ نظرات آنها در جلسات بحث گروهى و مصاحبه هاى عميق جمع آورى شد. داده ها، علاوه بر نظرات بيان شده شركت كنند كان، شامل اشكال مختلف تعاملات و موافقت ها و يا مخالفت هاى آنان با نظرات اعمال شده توسط دها سايرين در بحثهاى گروهى و... نيز بود. ساير روشهاى

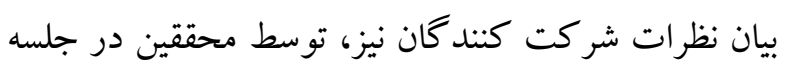
ثبت گرديد. براى جمع آورى داده ها، 4 مورد بحث

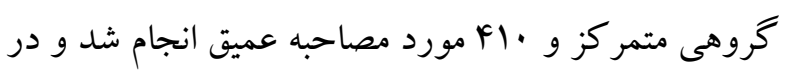
مواردى كه افراد رضايت داشتند براى ضبط جلسات بحث ورث كروهى و يا مصاحبه مورد نظر، با فرمت صوتى اقدام كرديد. بهطور كلى صحبت ها، فرم خلاصه يافته ها، شكل اصلى داده هاى اين بزّوهش بودند. محققان براى انجام مصاحبه عميق، در حين انجام مصاحبه

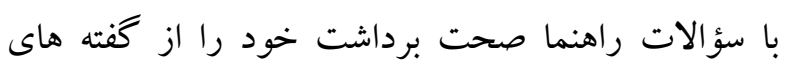
شر كت كنند كان كنترل مىنمودند. در مورد بحث گروهى، بعد از تشكيل جلسه بحث گروهى

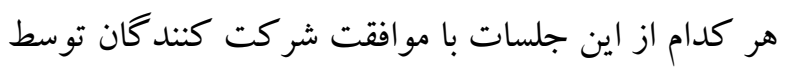
دستخاههاى ركوردر الكترونيكى ثبت و ضبط شد. علاوه بر آن در هر كدام از جلسات وضعيت و اشكال غير وربال شركت كنند كان توسط محقق اصلى و يادداشت بردار ثبت مى گرديد. محقق اصلى به عنوان گردانده جلسه و فرد ياداشت بردار آموزش ديده، هر دو نفر مراقب بودند كه 


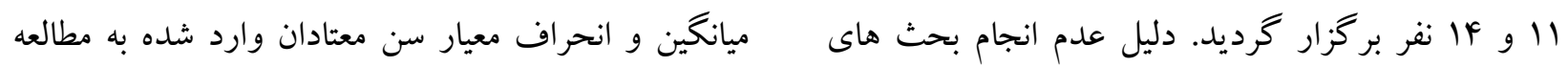

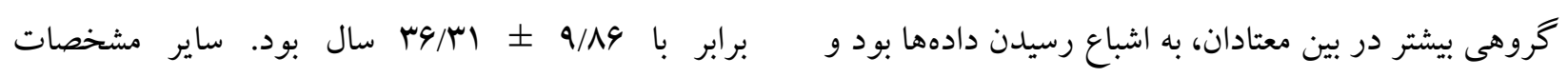

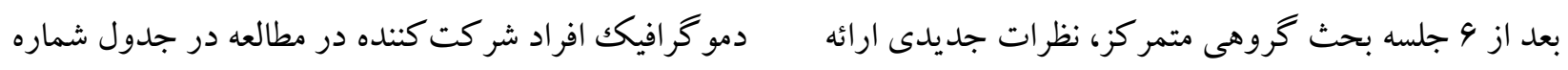
ا خلاصه شده است.

جدول شماره ا: مشخصات دمو گر افيك افراد شر كت كننده در مطالعه

\begin{tabular}{|c|c|c|}
\hline فراوانى (درصد) & سطوح متغير & متغير \\
\hline $10(\% / r / 94)$ & 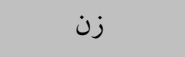 & جنسيت \\
\hline$r q \Delta(/ .99 / \mu \psi)$ & مرد & \\
\hline$M r \cdot(\% V \Lambda / \cdot \Delta)$ & مجرد & وضعيت تاهل \\
\hline$৭ \cdot(/ / r \backslash / ৭ \Delta)$ & 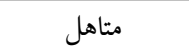 & \\
\hline $11(\% F / F q)$ & بى سواد. & تحصيلات \\
\hline$q \cdot(\% / r \backslash / q \Delta)$ & ابتدايى & \\
\hline $195(/ / \% 9 / \Delta 1)$ & راهنمايى & \\
\hline $111(\% \mathrm{rV} / \cdot \mathrm{V})$ & دييلم & \\
\hline $1 \Lambda(\% / F / \Gamma q)$ & فوق دييلم & \\
\hline $11(\% / / 9 \Lambda)$ & ليسانس و بالاتر & \\
\hline
\end{tabular}

از بالا به بِائين بر اساس فراوانى نظرات شركت كندكان همانطور كه در نتايج جدول ا مشاهده شود. بيش از 99٪ معتادان وارد شده مطالعه مرد بودند. بيشتر معتادان با وجود خلاصه شده است. ميانگين سنى بالا در زمان انجام مطالعه مجرد بودند. حدود 9ץ \% معتادان تحصيلات دييلم و زير دييلم داشتند. نتايج نشان داد كه در مواردى سن شروع اعتياد ها سالكى بوده است اما متوسط سن شروع اعتياد در مردان 19/9V سال و

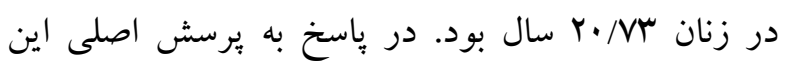
مطالعه كيفى يعنى علت اصلى شروع مصرف مواد، نتايج بر اساس تم هاى به دست آمده و آناليز تم ها' در جدول (r) خلاصه شده است. لازم به ذكر است كه در جدول شماره (Y)، ترتيب قرار گرفتن نظرات شر كت كنند گان در مطالعه 
جدول r. علل تأثير گذار در شروع مصرف مواد (مصرف مواد در بار اول) از ديدگًه افراد معتاد

\begin{tabular}{|c|c|c|}
\hline نظر ات شاخص شر كت كنند & زير طبقه (sub category) & طبقه (category) \\
\hline 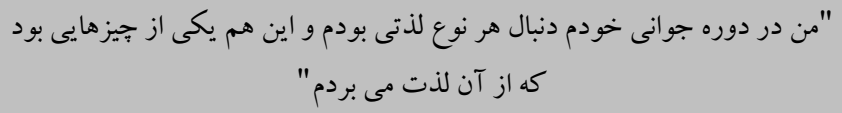 & ل لذت & 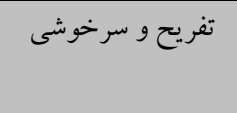 \\
\hline "مو اد از همان ابتدا به من شادى مى بخشيد و من با كشيدن آن شاد مى شدم" & شادى آور بودن مواد مخدر & \\
\hline " واقعاً براى من جالب بود كه مواد جطور است و خودم كنجكاو بودم" & كنجكاوى & 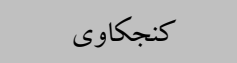 \\
\hline "من بار اول فقط توسط دوستانم ييشنهاد مصرف را كرفتم" & ي بيشنهاد دوستان & 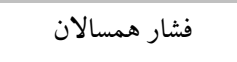 \\
\hline "واقعاً بار اول دوستانم من را به زور وادار به مصرف مواد نمودند" & اجبار دوستان براى مصرف & \\
\hline " دوستان من اخر مواد نمى كشيدم نه با من دوستى مى كردند و گاهى من را & $\begin{array}{l}\text { دنبالهروى كور كورانه از دوستان و راهى } \\
\text { براى ظاهر شدن }\end{array}$ & \\
\hline "واقعاً مى ترسيدم دوستانم من راديخر به جمع خود راه ندهند" & ترس از نيذيرفتن در جمع دوستان & \\
\hline "واقعاً من خودم در زمينه مواد هيج آكهى نداشتم نمىدانستم عواقبش جيه" & عدم آكاهى از عو اقب مصرف مواد & نآكاهى و دانش بيائين \\
\hline "من كه زياد هم درس نخواندم همان دوران ابتدايى درس را تركك كردم" & تحصيلات پيائين & \\
\hline "من بدرم و داداشم معتاد بودند خوب من هم در كنار آنها با اعتياد بزركك شدم" شومرم من را معتاد كرد" & 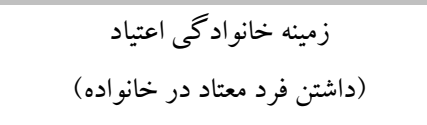 & مشكلات خانو ادگى \\
\hline "من تنها زندگى مى كردم و كسى را نداشتم و هميشه دنبال راهى براى خلاص & تنهايى & \\
\hline " خانم بنده طلاق گرفتند واقعاً نمى دانستم جر ا بِ از آن ناخواسته سمت مواد & شكست در ازدواج & \\
\hline 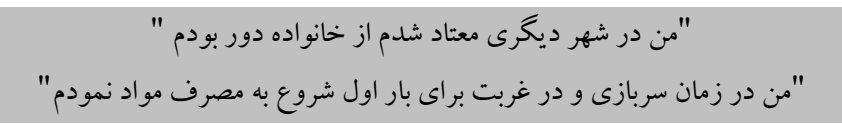 & دورى از محيط خانواده & \\
\hline 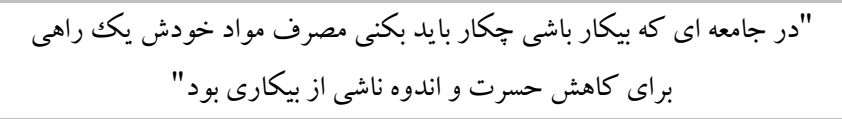 & 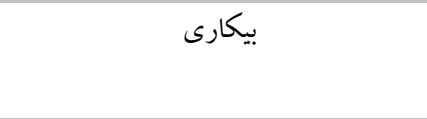 & 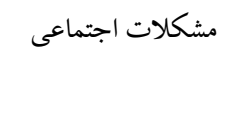 \\
\hline "هر جا مىرفتى جلو جشمت مواد مخدر بود الآن هم همينطوريه " & رايج بودن مواد مخدر در جامعه & \\
\hline "من در محيط جامعه و براى تقويت و ارضاى نيازهاى جنسى سراغ مواد مخدر & راهى براى تقويت ميل جنسى & 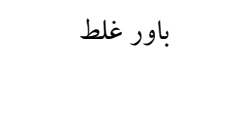 \\
\hline " من خودم اول بار به همين خاطر رفتم سراغ مواد جون بيمار بودم و درد داشتم & راهى براى درمان درد و بيمارى & \\
\hline "من به خاطر زيبا شدن جششمهايم ابتدا حشيش مى كشيدم بعد معتاد شدم" & $\begin{array}{c}\text { اعتياد به عنو ان راهى براى زيبا شدن و جوان ماندن } \\
\text { زبل }\end{array}$ & \\
\hline 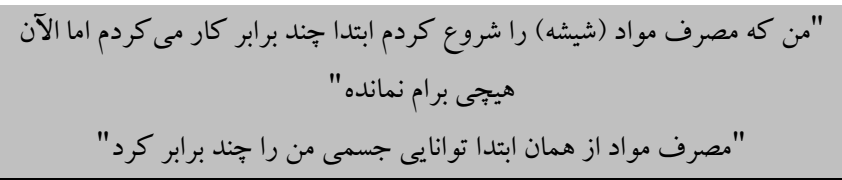 & 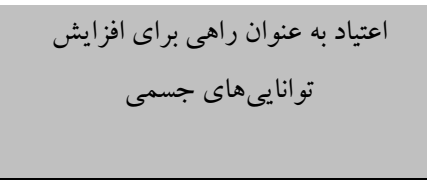 & \\
\hline
\end{tabular}




\begin{tabular}{|c|c|c|}
\hline "من جون يول زيا داشتم دنبال هر كارى مىرفتم و اعتياد هم يكى از اين كارها & رفاه مادى & رفاه و غرور \\
\hline 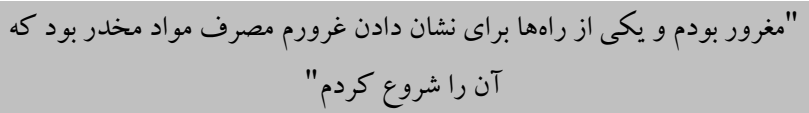 & داشتن غرور كاذب & \\
\hline
\end{tabular}

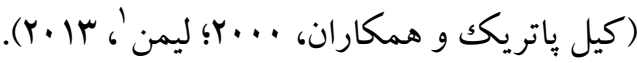
يكى ديخر از مهمترين يافتهاى مطالعه حاضر نقش فشار همسالان در شروع اعتياد بود كه اين يافته هم با نتايج

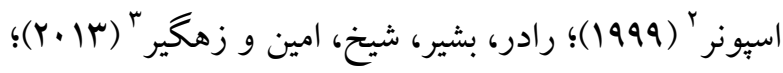

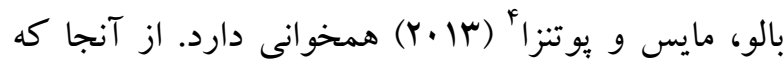
نوجوانان در سنين نوجوانى مدت زمان زيادى از اوقات فراغت و حتى اوقات درسى خود را با همسالان طى ملى مى كنند به نظر مى رسد اين متغير به همراه محيط زندكى افراد نقش بسيار مهمى در شكل كيرى رفتارهاى فرد به ويزه روى آوردن به مصرف مواد مخدر يا هر كونه آسيب مهري اجتماعى ديخر داشته باشد. در واقع در بسيارى موارد افراد

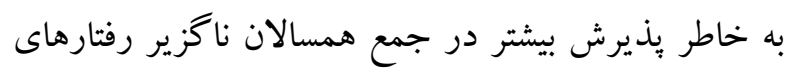

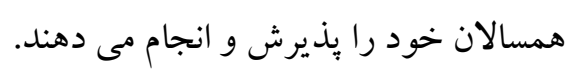

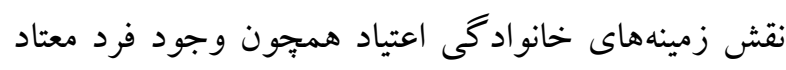
در خانواده، شكست در ازدواج و تنهايى فرد در شروع مصرف مواد مخدر به عنوان يك يافته مهم ديخر در اين مطالعه مطرح است كه نتايج مطالعات زيادى در دنيا از

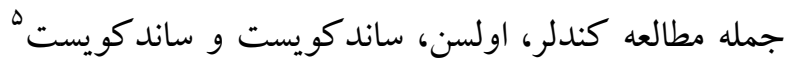
(r.|r) و طاهرى، اميرى، حسينى، محسن بور و داويدسن، (Y.19) با اين يافته مطابقت دارد. به نظر مى رسد مؤلفه هاى فوق محيط زندگى فرد را نا متعادل ساخته و زمينه

$$
\text { آسيب بذيرى فرد را بيشتر مى كند. }
$$

\footnotetext{
${ }^{1}$ Lyman

${ }^{2}$ Spooner

${ }^{3}$ Rather, Bashir, Sheikh, Amin \& Zahgeer

${ }^{4}$ Balogh Mayes \& Potenza

${ }^{5}$ Kendler, Ohlsson, Sundquist \& Sundquist

${ }^{6}$ Taheri, Amiri, Hosseini, Mohsenpour \& Davidson
}

بر اساس آنجه كه در جدول شماره (Y) خلاصه شده است از نظر فراوانى علل شروع اعتياد در معتادان موردبررسى، لذتجويى افراد و دنبال تفريح بودن بيشترين علت ذكر شده براى شروع مصرف بوده است و يس از آن كنجكاوى، فشار همسالان، نآكاهى، مشكلات داخل خانواده و مشكلات داخل اجتماع در رده هاى بعدى قرار داشتند. در بعضى از موارد هم علل اصلى شروع اعتياد وجود برخى باورهاى نادرست در بين افراد جامعه است. در تعدادى ديخر از معتادان علل مصرف مواد مواردى همجيون داشتن غرور و رفاه مادى ذكر شده است.

\section{بحث و نتيجه كيرى}

طبق نتايج اين مطالعه متوسط سن شروع اعتياد در معتادان شهر سنندج تقريباً . r سالكى بوده است. نتايج مطالعه حاضر در زمينه شناخت علل شروع اعتياد يا به عبارتى مصرف مواد مخدر در بار اول كه حاصل نظرات شركت

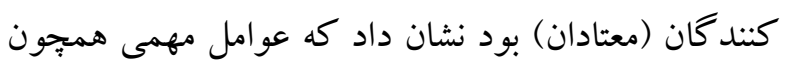
تفريح و سرخوشى، كنجكاوى، فشار همسالان، نآكاهى و

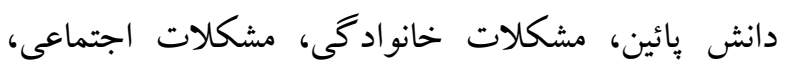
باورهاى غلط در فرد، رفاه مادى و غرور به ترتيب فراوانى تونى عو امل اصلى تأثير گذار در شروع اعتياد معتادان بوده است. بر اساس نتايج مطالعه حاضر بيشترين علل تأثير گذار در مصرف بار اول مواد مخدر توسط جوانان از نظر فراوانى، لذت جويى، دنبال تفريح بودن و كنجكاوى بود كه با تعداد زيادى از مطالعات انجام شده در دنيا مطابقت دارد 
آنجا كه با همه افراد شركت كننده در مطالعه مصاحبه هاى عميق به عمل آمد سعى شد كه از ديد كاه خود معتادان علل

$$
\text { شروع اعتياد آنها را به دست آورد. }
$$

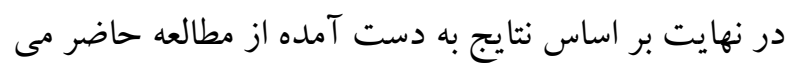
توان نتيجه گرفت كه عواملى همجيون تفريح و سرخوشى،

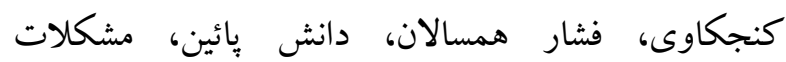
خانوادگى، مشكلات اجتماعى و باورهاى غلط در فرد به هيه ترتيب فراو انى مهمترين عوامل تأثير گذار در شروع مصرف مواد مخدر در سنندج است. بر همين اساس لازم است در بحث مرتبط با مداخلات بيشخيرانه، توجه به هر كدام از

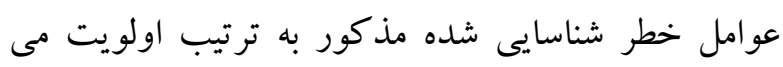
تواند راهى فراروى مسئولان سيستم سلامت قرار دهد.

\section{تشكر و قدردانى}

مطالعه حاضر با نظارت و حمايت مالى معاونت بهداشتى دانشگاه علوم يزشكى كردستان انجام گرديد. لذا محققان بر خود لازم مىدانند كه مراتب تشكر و قدردانى خود را نسبت به همكاران محترم اين معاونت و همجينين مركز تحقيقات عوامل اجتماعى مؤثر بر سلامت كردستان ابراز

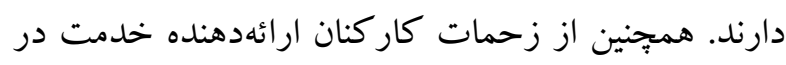
مراكز كذرى ترك اعتياد و مركز مشاوره بيمارىهاى رفتارى سنندج به خاطر همكارى در اجراى مطالعه تشكر و ورئر

$$
\text { قدردانى مى گردد. }
$$

\section{References}

Ahmadi, J., \& Hasani, M. (2003). Prevalence of substance use among Iranian high school students. Addictive behaviors, 28(2), 375-379.

Balogh, K. N., Mayes, L. C., \& Potenza, M. N. (2013). Risk-taking and decision-making in youth: Relationships to addiction vulnerability. Journal of behavioral addictions, 2(1), 1-9.
نتايج مطالعه حاضر نشان داد كه مشكلات اجتماعى همجيون باورهاى غلط، فقر، بيكارى، شيوع بالاى مصرف مقل مواد مخدر و رايج بودن خريد و فروش مواد در سطح جامعه هم از دلايل ديخر روى آوردن جوانان مورد مطالعه به مصرف مواد مخدر بود. بسيارى از مطالعات انجام شده در اين زمينه هم ارتباط قوى شروع مصرف مواد باعوامل اجتماعى مذكور نشان داده اند كه از آن جمله مى توان به ريه

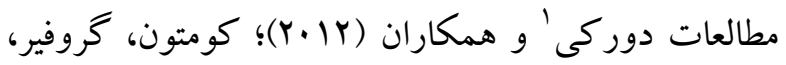

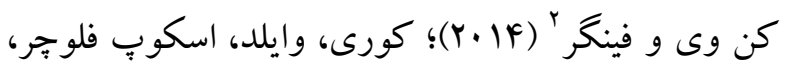

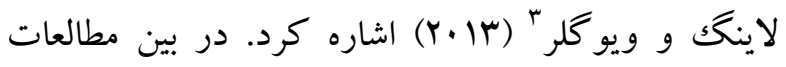

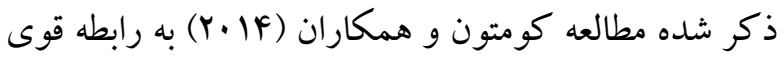
بين بيكارى و مصرف مواد مخدر اشاره كرده است. اكرجه مواردى كه در بالا اشاره شدند همجيون بيكارى، محيط

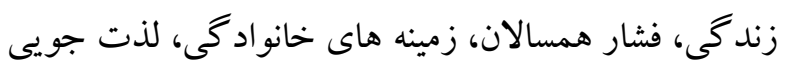
و غيره به عنوان مهمترين متغيرهاى تأثير كذار در شروع

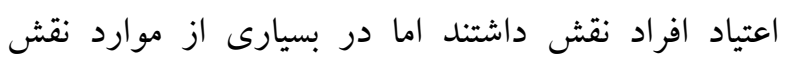
سينرزيستى اين عوامل در كنار هم مطرح است و در افرادى كه تعداد بيشترى از عوامل خطر بالا را همزمان تجربه مى كنند به نظر مىرسد كه شانس روى آوردن افراد به مصرف مواد را بيشتر مى كند. مطالعه حاضر در نوع خود اولين مطالعهاى است كه در استان كردستان و مطابق با ريشه ها و الكوهاى اعتياد در بستر فرهنكى شهر سنتدج صورت گرفت. يكى از نقاط قوت اين مطالعه، دستيابى به علت و عوامل تأثير گذار در شروع مصرف مواد مخدر با استفاده از روشهاى كيفى بـ بود. يرواضح است كه با توجه به هند عاملى بودن اعتياد به مواد مخدر، يافنن و استخراج همه علت هاى شروع مصرف مواد با روش هاى كمى امكانيذير نيست. در اين مطالعه از

\footnotetext{
${ }^{1}$ Durkee

${ }^{2}$ Compton, Gfroerer, Conway \& Finger

${ }^{3}$ Currie, Wild, Schopflocher, Laing \& Veugelers
} 
Botvin, G. J. (2000). Preventing drug abuse in schools: Social and competence enhancement approaches targeting individual-level etiologic factors. Addictive behaviors, 25(6), 887-897.

Compton, W. M., Gfroerer, J., Conway, K. P., \& Finger, M. S. (2014). Unemployment and substance outcomes in the United States 2002-2010. Drug and alcohol dependence, 142,350-353.

Currie, C. L., Wild, T. C., Schopflocher, D. P., Laing, L., \& Veugelers, P. (2013). Illicit and prescription drug problems among urban Aboriginal adults in Canada: the role of traditional culture in protection and resilience. Social Science \& Medicine, 88, 1-9.

Day, C., Nassirimanesh, B., Shakeshaft, A., \& Dolan, K. (2006). Pattems of drug use among a sample of drug users and injecting drug users attending a General Practice in Iran. Harm reduction journal, 3(1), 2.

Durkee, T., Kaess, M., Carli, V., Parzer, P., Wasserman, C., Floderus, B., ... \& Brunner, R. (2012). Prevalence of pathological internet use among adolescents in E urope: demographic and social factors. Addiction, 107(12), 2210-2222

Essau, C. A. (Ed.). (2008). Adolescent addiction: Epidemiology, assessment, and treatment. Elsevier.

Goodman, A. (1990). Addiction: definition and implications. British journal of addiction, 85(11), 1403-1408.

Kendler, K. S., Ohlsson, H., Sundquist, K., \& Sundquist, J. (2013). Within-family environmental transmission of drug abuse: a Swedish national study. JAMA psychiatry, 70(2), 235-242.

Kienast, T., Stoffers, J., Bermpohl, F., \& Lieb, K. (2014). Borderline personality disorder and comorbid addiction: epidemiology and treatment. Deutsches Ärzteblatt International, 111(16), 280.

Kilpatrick, D. G., Acierno, R., Saunders, B., Resnick, H. S., Best, C. L., \& Schnurr, P. P. (2000). Risk factors for adolescent substance abuse and dependence: Data from a national sample. Journal of consulting and clinical psychology, 68(1), 19.

Lyman, M. D. (2013). Drugs in society: Causes, concepts, and control. Routledge.

Mokri, A. (2002). Brief overview of the status of drug abuse in Iran. Arch Iranian Med, 5(3),184-90.

Rather, Y. H., Bashir, W., Sheikh, A. A., Amin, M., \& Zahgeer, Y. A. (2013). Socio-demographic and clinical profile of substance abusers attending a regional drug de-addiction centre in chronic conflict area: Kashmir, India. The Malaysian journal of medical sciences: MJMS, 20(3), 31.

Sobell, L. C., Sobell, M. B., \& Ward, E. (Eds.). (2013). Evaluating alcohol and drug abuse treatment effectiveness: Recent advances. Elsevier.

Spooner, C. (1999). Causes and correlates of adolescent drug abuse and implications for treatment. Drug and Alcohol Review, 18(4), 453-475.

Stanton, M. D., \& Shadish, W. R. (1997). Outcome, attrition, and family-couples treatment for drug abuse: A meta-analysis and review of the controlled, comparative studies. Psychological bulletin, 122(2), 170.

Taheri, Z, Amiri, M., Hosseini, M., Mohsenpour, M., \& Davidson, P. M. (2016). Factors affecting tendency for drug abuse in people attending addiction treatment centers: A quantitative content analysis. Addiction Research and Therapy, 7(270), 1-4.

Whiteford, H. A., Degenhardt, L., Rehm, J., Baxter, A. J., Ferrari, A. J., Erskine, H. E., ... \& Burstein, R. (2013). Global burden of disease attributable to mental and substance use disorders: findings from the Global Burden of Disease Study 2010. The Lancet, 382(9904), 1575-1586.

Wise, R. A., \& Koob, G. F. (2014). The development and maintenance of drug addiction. Neuropsychopharmacology, 39(2), 254. 